\title{
Post-normal Science, a Component of Adaptive Engineering
}

\author{
Jonathan D.J. VanderSteen \\ University of Guelph \\ jovander@uoguelph.ca
}

\author{
Benjamin Kelly \\ McMaster University \\ kellybw@mcmaster.ca
}

\begin{abstract}
Past reliance on highly-specialized, disciplinebased knowledge has not only led to great prosperity, but it also has the tendency to ignore broader social and environmental contexts, resulting in decreased resilience and unintended consequences. This decreased resilience is manifested in engineering education and practice through a busier, less integrated curriculum, an inability to work across disciplines and a lack of connection with the end-user. We propose a new curriculum model called Adaptive Engineering. Our pedagogy does not strive to replace the curriculum, but rather supplement it by addressing certain values that are necessary to improve resilience. Adaptive Engineering promotes reflexive, preventive, and multidisciplinary engineering with practitioners who are community focused, socially just, and who make decisions through Learning Alliances. Our resilient model essentially draws from two key characteristics of post-normal science: 'extended peer communities' and 'extended facts.'
\end{abstract}

\section{Introduction}

Due to an over-dependence on the paradigm of pure science and a lack of integrated scholarship, universities have failed to address the current social, economic, and environmental problems [1]. To promote better integration, and to be relevant in the 21 st century, engineering ed- ucators must train their students to be aware of the context in which they will soon work. A scholarship of engagement often exists in tension with the paradigm of pure science. Resolving this tension requires reflection on the ultimate goals of education and professional socialization.

Engineering educators and students alike must constantly ask, "Why do we need more engineers?" There are important reasons that can be given to answer this question, but without sufficient reflection on the purpose of curriculum, engineering education can easily be framed as simply a necessary tool for productivity, profit, and national competitiveness. These things are not bad in themselves, but when removed from many less-measurable intrinsic values, engineering decisions are easily made without an understanding of the influence that technical systems have on the individual, the community, and the environment.

A reliance on the paradigm of pure science and the subsequent performance metrics has lead to much prosperity. It has also led to the emergence of the expert and a knowledge infrastructure dominated with highly-specialized knowledge. This domination, control and reductionism has been necessary for many accomplishments of Western (or Universal) science, but has also resulted in many unforeseen consequences such as increasing health care costs, global unemployment, dramatic escala- 
tion in mental health problems, a growing gap between the rich and the poor, large national deficits, and ecological decline. An over reliance on highly-specialized knowledge has resulted in a decline in resilience.

Healthy systems must always be able to adjust to new conditions. The engineering profession, in general, and specifically, the engineering curriculum, is often said to be slow to adjust to change. Current engineering graduates are faced with an immensely different world than what their parents faced a generation earlier, but much like a generation ago, the undergraduate curriculum rarely teaches beyond the narrow confines of highly-specific discipline-based knowledge. While there are many voices for a broader education, students are rarely given more than one or two courses on topics related to broader technology impact. These broadening courses are often seen by the student to be of marginal importance relative to technical coursework [2].

It is vital that a new curriculum emerge. One that can integrate a focused disciplinebased scientific perspective with an integrated approach to address our growing vulnerability and reliance on the status quo of self interest and professional tunnel vision. This paper draws from current trends in engineering and education to present some important ideas on how the engineering curriculum can evolve. The intentions of this paper are to address a problem within engineering as a whole by dealing specifically with engineering education. Assuming engineering educators are paying attention beyond the paradigm of pure science, they should be able to immediately recognize the need for praxis. Pedagogy feeds into practice and in turn, practice should feed into pedagogy.

\section{What's Wrong?}

A complete diagnosis of the engineering curriculum would take far more pages than appro- priate for this paper, but some important observations can be made: First of all, there are many demands - some engineers are demanding more soft skills such as communication and interpersonal skills. Others worry that this comes at the expense of fundamentals. Others suggest that we must sacrifice some of the fundamentals to teach important computational tools to prepare young engineers for the 'realworld' work force. A closer relationship with industry is the key for relevance and balanced budgets for some people, while others suggest that corporate interests must be resisted and that sustainability, (often defined very loosely) be the focus of the curriculum. This increased demand on curriculum and the decreased time for department and faculty planning has led to an increasingly more disjointed curriculum.

Beyond simply not having the time or energy to create an integrated curriculum among teaching colleagues, it is becoming very difficult for individual engineering educators to move out of a discipline-specific paradigm. This effectively removes much of the context from engineering and results in little knowledge of the influence that technology has on the individual, community, and environment. As a result, engineers work in their specific areas of expertise, often unable to deal with the negative consequences that fall beyond their competence. Worse, there is no real way to measure success or failure except using indicators that exist within the discipline. As a result, unintended consequences exist and in turn, are converted to technical problems for other specialists. Engineers are thus, impotent to make decisions that have local communities and the biosphere in mind if they insist on working in this paradigm.

Thirdly, while the ultimate goal of engineering education is to train practitioners to transfer scientific knowledge into useful goods and services, much of the work conducted in academic institutions finds little translation in the 
real world. As the complexities of our societies and institutions increases, there is a growing sense that excellent technical research and teaching is often not finding an end-user [3].

Finally, engineering education is said to promote an undemocratic relationship with technology. Applications that are taught are not initiated by the end user, but instead are motivated by profitability and competitiveness. As a result, science and technology is seen as elitist, as it only addresses the needs of the elite, and the researchers themselves [4].

As a profession, engineering must seriously fulfill their obligation to treat the publics welfare as paramount. These deficiencies should humble the profession to ensure that professional self-interest does not get in the way of other normative obligations. These deficiencies should not be seen as an absolute failure - we always fall below the standards set, both personally and professionally. We must recognize our current situation and struggle to meet the ideals set before us. A new curriculum model can help facilitate this transformative process.

\section{Adaptive Engineering}

Todays university students want a different type of education - a more complete education that deals with how the world works, but also with how to live in the world and improve it. An engineering education must deliver this without deskilling the profession. This cannot be done by adding more to the curriculum, it is already very full, but through taking a new approach to teaching. The problem is not that there is not enough material in the curriculum, but that the curriculum focuses on the wrong values. An adaptive engineering curriculum is necessary for increased resilience and will include a number of characteristics [5], highlighted below.

An adaptive engineer advocates for preventive engineering. Preventive engineering is es- sential, but currently, the bulk of engineering research is end-of-pipe work. Engineering design and decision-making, like any good control system, requires a negative feedback loop where the product or output (beneficial or otherwise) of the design cycle is fed back into the design criteria. Preventive engineering is not possible if only discipline-based, highlyspecialized knowledge is used in design and decision making - it requires looking out of a specific discipline. This involves moving as much information as possible into the analysis and ensuring that human, social, and environmental issues are not simply converted into technical problems. It ultimately requires an awareness of the limitations of disciplinespecific knowledge [2].

An adaptive engineer has increased awareness or reflexivity. Reflexivity refers to the human capacity to use the available information to make important life decisions, and view the world from others perspectives, but it also refers to the ability to consider the consequences of actions that could impact carefully made plans, knowing full well that one can never completely know all consequences. In the case of the engineer, this is an integrated understanding of socio-technical systems. This requires the engineer to identify values beyond performance metrics [6].

An adaptive engineer is a broad thinker who strives for multidisciplinary and interdisciplinary interactions. In order to be preventive and reflexive, an engineer must be a broad thinker, willing to engage in multidisciplinary and interdisciplinary conversations and collaboration. While much richness comes from these interactions, it must be noted that true multidisciplinary work is difficult in the current knowledge infrastructure. Expert knowledge is what is rewarded and the demand for novel work is easier within the confines of a specific discipline. The Canadian Engineering Accreditation Board demands that gradu- 
ates understand the impact of engineering on society and the environment and this can only be done with broad thinking - engineering schools have yet to take this seriously.

An adaptive engineer works for social justice. A powerful and increasingly popular way to foster communication skills is through community involvement. This involvement must be done with justice and not with charity [7]. The motivations should not be altruistic but with the intention of creating a more resilient community through the removal of wealth and opportunity gradients. This must also include a constant critique of the status quo. Engineering educator Ursula Franklin suggests that engineering education must look beyond market growth and must promote justice, restore reciprocity, favour people over machines, promote conservation over waste, and favour reversibility over irreversibility [8].

An adaptive engineer is community focused. Most engineers will find themselves working on universal technologies due to the globalization of the markets. There is good that come from this work, but there are many problems as well - mostly rising from the fact that universal technologies are primarily developed with experts with highly-specialized knowledge. An adaptive engineer will know that resilience comes through seeing multiple ways of knowing and doing. Moving away from discipline-based knowing and doing requires engineers to apply knowledge gained through experience, culture, and cross-discipline communication. These activities will intrinsically link the engineer to his or her community; engineers should work to make their own communities stronger.

An adaptive engineer makes decisions through Learning Alliances. A Learning Alliance, or platform for multiple-stakeholders to involve end-users in all phases of innovation, development, implementation, and upkeep of technology, offers the best way for the adaptive engineer to make decisions. Working with local community with various end-users and lay expertise will intrinsically result in both selfreflection and a diversity of approaches and eventually a better innovation, if the right people are brought to the table. Bringing multiple stakeholders to the table has the potential to create a more just, democratic, and inclusive technology. Alternative thinking can occur in these informal settings, which is a great way to foster alternative communities with increased resilience [4].

An adaptive engineering curriculum philosophy aims to address the uncertainty and risks associated with the landscape in which engineers must work. This adaptive engineering model draws from two key concepts associated with post-normal science.

\section{Post-normal Science}

The notion of post-normal science arose approximately 20 years ago due to the growing awareness to the limitations of science in Western societies [9]. Post-normal science acknowledges that conventional, scientific methods are not adequate for dealing with the uncertainty and risk that surround contemporary society because of the stringent and isolating views of expert knowledge and their undemocratically closed approach. Adaptive engineering, similarly, encourages thinking about engineering more in terms of relationships and less in terms of gadgets. The adaptive engineering model described in this paper, draws from 'extended peer communities' and 'extended facts,' two key characteristics of post-normal science.

Post-normal science requires 'extended facts' that go beyond the discipline, accommodating knowledge gained through experience and culture as well as from other areas of academic study. Rather than overlooking more traditional and indigenous experiences, an adaptive engineer is not beyond exploring epistemological and methodological ap- 
proaches as a means of solving local problems. To be multidisciplinary, the engineer must risk ventures in fields where he or she is not an expert. These ventures are necessary for an engineer to avoid end-of-pipe solutions and to ensure reflexivity.

At the same time, post-normal science requires that engineers look outside of their discipline to work in 'extended communities.' While it is possible to imagine an engineer with knowledge from a variety of fields, ultimately clear communication between people in other disciplines and with other interests is the most practical way to achieve the necessary breadth. This requires a conscious effort to present ideas in a more accessible way, avoiding unfamiliar jargon or nomenclature. Learning Alliances offer an appropriate platform for engineers to meet with community members, lay experts, and discipline-based experts. But any extended peer community must be diverse; it must include people who can think beyond the scientific approach. A Learning Alliance is not intrinsically good in itself, but must be carefully set up to bring the right people to the table. This must include people who are interested in the health and viability of the local ecosystem and economy and not just the interests of national and global corporations.

The inability of experts to acknowledge and integrate lay knowledge has had drastic ramifications. One such example is the Cod fisheries collapse of the coast of Newfoundland. It is believed that the near decimation of fish be attributed to experts' false sense of confidence in their models of sampling, prediction and control regarding the management of cod populations. Scientists, government officials and industry refused to recognize the concerns and incorporate the knowledge of local fishermen who over many years had warned of the dangers inherent in offshore commercial fishing. Unfortunately indigenous knowledge, being viewed as merely 'subjective' and 'ex- periential', never had a chance of penetrating the dogmatism of scientific management [10]. Similar case studies would provide instructors and students with insight on how to develop best practices.

Extended communities and extended facts are both necessary to ensure that solutions go beyond the surface and get to the root of the problem. Service learning so often exists within a discipline and often reproduces the status quo. Transformational work can only occur with a scholarship of engagement with holistic, integrated, and collaborative thinking to get at root causes. If Community Based Engineering focuses solely on input/output raios, it is bound to fail like many earlier initiatives.

\section{How Do We Apply Concepts?}

Perhaps the most challenging aspect of training engineers as professionals will be to provide them with an institutional context that allows them to move beyond the paradigm of normal, objective science. Adaptive engineers will need to be trained to accommodate, adjust, and be stewards of nature through understanding cycles, rhythms, and patterns and to ultimately let go of the desire for a conquest and control of nature - a large paradigm shift.

This paper up to this point has been a diagnosis, the easy part; it is much more difficult to talk about the treatment. There is no concrete algorithm to introduce a new philosophy such as Adaptive Engineering in the curriculum, but again, some general discussion can be useful here. Future work will focus more on practical implementation and assessment.

Regardless of the concrete ways in which Adaptive Engineering is introduced into a curriculum, a couple of approaches are necessary. All engineering students should be offered a course that deals with engineering, society, and the biosphere. Students must be made aware of the tension between resistance and accommodation of the way things are currently done. 
The courses offered by Willem Vanderburg at the University of Toronto, based on his books, 'The Labyrinth of Technology' and 'Living in the Labyrinth of Technology' [11, 2] offer an example of what these courses could be.

One of the most important concrete steps is for engineering educators to encourage more knowledge acquisition through personal experience. Much like Jane Jacobs walked many urban miles in order to best discuss city planning, engineers should be encouraged to experience processes and products through a thorough experience This should not simply include field trips, but opportunities to really experience various engineering processes and products. For example, the design of a water treatment plant could involve visiting a variety of treatment plants, working in the plant, and conduct interviews with operators and managers. Similarly, design projects could be carried out over multiple years, include connections with industry and community, and involve design on paper, analysis, and hands-on construction or implementation.

One more pedagogical tool that could help introduce Adaptive Engineering ideals would be to adapt the concept of Dutch "science shops" to the engineering curriculum. These science shops were set up as an interface between the community and the university where public-interest groups, community organizations, and concerned citizens could discuss and suggest research ideas on topics concerning social and technological issues [12]. Engineering students could, in turn, frame their course material around some of these challenges.

In the end, engineers are only really useful to humanity if they can address concerns regarding risks to human health, community wellbeing, and the integrity of the biosphere. Engineers can make useful contributions here if their approach is one of cooperation and not of absolute control. It is our belief that engineers can address these issues through adap- tive engineering that draws from post-normal science.

\section{References}

[1] Ernest L. Boyer. Scholarship Reconsidered: Priorities of the Professoriate. The Carnegie Foundation for the Advancement of Teaching, 1990.

[2] Willem H. Vanderburg. Living in the Labyrinth of Technology. University of Toronto Press, 2005.

[3] A Report Card on Canada. Technical report, The Conference Board of Canada, 2008.

[4] B. Kelly and Kh. Farahbakhsh. Innovative Knowledge Translation in Urban Water Management. The International Journal of Technology, Knowledge, and Society, 4(3):73-84, 2008.

[5] J. D. J. VanderSteen. Adaptive Engineering. Bulletin of Science, Technology and Society, Forthcoming.

[6] Peter T. Robbins. The Reflexive Engineer: Perceptions of Integrated Development. Journal of International Development, 19:99-110, 2007.

[7] Sam Marullo and Bob Edwards. From Charity to Justice. American Behavioral Scientist, 43(5):895-912, 2000.

[8] Ursula M. Franklin. The Real World of Technology. CBC Enterprises, 1990.

[9] S. Funtowicz and R. Ravetz. Science for the Post-Normal Age. Futures, 25:735-755, 1993.

[10] Dean Bavington. Science Manages the Sea. Ideas on the Nature of Science. Goose Lane Editions, 2009.

[11] W.H. Vanderburg. The Labyrinth of Technology. University of Toronto Press, 2000.

[12] Richard E. Sclove. Democracy and Technology. The Guilford Press, 1995. 